\title{
A STUDY ON THE EFFECT OF DIAGONAL CRACKS OPENING ON THE FAILURE BEHAVIOR OF RC BEAM-COLUMN JOINT WITH MECHANICAL ANCHORAGES BY 3D RBSM
}

\author{
KOHEI NAGAI* AND LIYANTO EDDY ${ }^{\dagger \dagger}$ \\ Institute of Industrial Science, The University of Tokyo \\ Tokyo, Japan \\ e-mail: nagai325@iiis.u-tokyo.ac.jp \\ ${ }^{\dagger}$ Institute of Industrial Science, The University of Tokyo \\ Tokyo, Japan \\ e-mail: eddy@iis.u-tokyo.ac.jp
}

Key words: beam-column joints, mechanical anchorages, meso-scale analysis, 3D RBSM

\begin{abstract}
Local reinforcement along the anchorages can be one way to avoid anchorage failure in the beam-column joints with mechanical anchorages. However, previous experimental work showed that different macroscopic behaviors were observed with different local reinforcement arrangements. The reason for such variations was not clarified since internal stresses and internal crack conditions are not well understood. It is considered that the opening of diagonal cracks in the beam-column joint plays an important role on the failure behavior. In this study, a meso-scale discrete analysis using 3D rigid body spring model (RBSM) is conducted to investigate this consideration. Parametric studies by 3D RBSM are conducted in which stirrups along the anchorages in the joint are modeled as deformed and plain bars. Based on the simulation results, different performances are predicted with different types of stirrups. Before the occurrence of diagonal cracks, bond performance along the development length of the anchorages depends on the number of stirrup and is not affected by the type of stirrup. Once diagonal cracks occur, the opening of diagonal cracks is affected by the type of stirrup. When stirrups are modeled as plain bars, slippage occurs easily between concrete and reinforcement and diagonal cracks then open readily. Furthermore, damage occurs at the top surface of the joint, leading to a decrease in capacity.
\end{abstract}

\section{INTRODUCTION}

Reinforcement congestion is particularly acute in those areas where reinforcement bars come together from multiple directions, such as at beam-column joints. Congestion in these joints leads to more difficulty in ensuring concrete compaction and adequate anchoring of the reinforcement and increased construction time. Mechanical anchorage is one way to reduce the reinforcement congestion in beam-column joints. Because it has an anchorage plate at the end of the anchorage, mechanical anchorage is shorter than conventional hooked bar and has simpler mechanical detail (Figure 1).

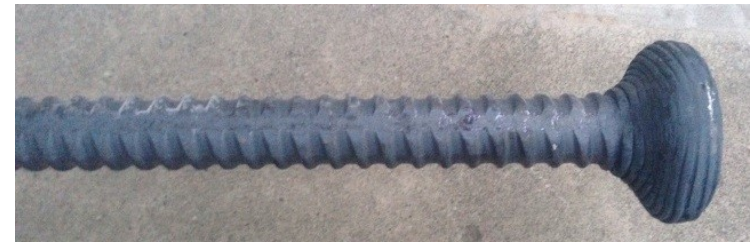

Figure 1: Mechanical anchorage. 


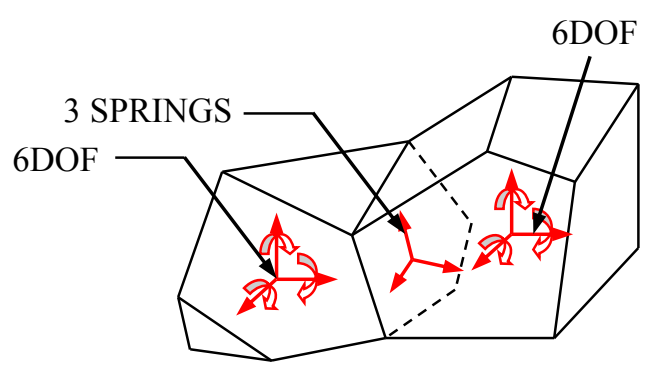

Figure 2: 3D RBSM mechanical model.

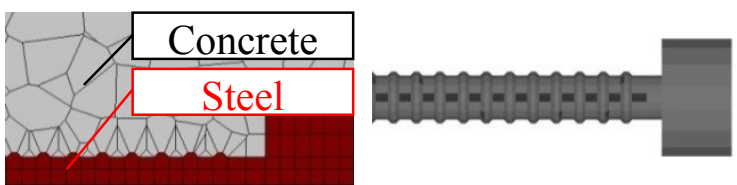

Figure 3: Mesh arrangement for concrete and re-bar.

However, if the mechanical anchorages are placed near the surface of a beam-column knee joint, anchorage failure may occur in the joint because of local stresses from the anchorage plates, particularly when the joint is loaded by a moment that tends to close the joint [1-3]. Local reinforcement placed along the anchorages is one way to avoid the danger of anchorage failure, but different macroscopic behaviors were observed with different local reinforcement arrangements. The reason for such variations was not clarified since internal stresses and internal crack conditions have not been well understood. Authors considered that the opening of diagonal cracks affects the macroscopic behaviour of the beam-column knee joints with mechanical anchorages [4]. In order to confirm this behavior, further studies are needed.

Numerical simulation can be a beneficial tool for understanding internal stresses and internal crack conditions. Meanwhile, experimental program will take time and is inefficient. Because a 3D simulation by modeling the 3D shape of the reinforcement including its ribs is needed, local stresses at meso-scale $(10-20 \mathrm{~mm}$ of size) need to be considered, and cracks should be introduced directly, a 3D discrete element analysis method called 3D Rigid Body Spring Model (RBSM) is appropriate. In our research group, 3D RBSM has been used to study the behaviour of reinforced concrete members by directly modeling the shape of the reinforcement in 3D, including its ribs [5-6].

Ultimately, the aim of this research is to investigate the effect of the opening of diagonal cracks on the failure behaviour of the beam-column joint with mechanical anchorages by 3D RBSM. Parametric studies are conducted by modeling stirrups placed along the anchorages as deformed and plain bars. In cases deformed stirrups, the simulation results are compared with the experimental results.

\section{NUMERICAL METHOD AND CONSTITUTIVE MODELS}

\subsection{Numerical method}

Simulations are carried out by 3D RBSM, proposed by Kawai et al. [7]. A three dimensional reinforced concrete model is formed from a mesh of rigid bodies. Each rigid body has six degrees of freedom, consisting of three translational degrees of freedom and three rotational degrees of freedom around certain points within its interior. Each is connected to other rigid bodies by three springs: two shear springs and one normal spring (Figure 2). To model a reinforced concrete member in $3 \mathrm{D}$, two types of element are used: concrete and steel. As the propagation of cracks in reinforced concrete is one of the most important factors affecting reinforce concrete behavior, the mesh arrangement in the model in RBSM is important. In order to prevent cracks propagating in a non-arbitrary direction, a random geometry in the form of a Voronoi diagram is used for element meshing. Concrete elements are modeled with a size of approximately $10 \times 10 \times 10-20 \times 20 \times 20 \mathrm{~mm}^{3}$, which is similar to the aggregate size, in order to ensure a similar cracking pattern to actual concrete. The geometry of steel elements is modeled accurately, with full 3D modeling of the reinforcement bar arrangement, in order to properly account for interlocking between reinforcement and concrete. The meso-scale mesh arrangement used for concrete and steel in this study is shown in Figure 3. The 
properties of the springs are determined such that the elements, when combined together, are able to predict accurately the response determined in laboratory scale material tests. The simulation system developed by Nagai et al. [8] is used.

\subsection{Constitutive model of elements}

Two types of elements are used to represent the behavior of reinforced concrete in this study.

(1) Concrete elements

As mentioned above, the shape of concrete elements is determined randomly using a Voronoi diagram. However, elements near steel elements are constructed manually in order to follow the actual 3D geometry of the reinforcement bars. Random element generation is thought to lead to accurate replication of concrete fracture process. The constitutive models for the normal and shear springs of the concrete elements are shown in Figure 4. In the compression zone, the normal spring of the concrete elements behave elastically, since compressive failure is not allowed at the meso scale. A crack, between two rigid bodies occurs when the tensile strength of the normal springs exceeds the tensile strength of the concrete elements $\left(f_{t}\right)$. After the tensile strength $\left(f_{t}\right)$ is exceeded, the tensile stress of the normal spring is assumed to decrease bi-linearly depending on the crack width between the two rigid bodies. In this study, the maximum crack width $\left(w_{\max }\right)$ is assumed to be $0.3 \mathrm{~mm}$ (Figure 4a). On the other hand, an elasto-plastic behavior is assumed for the shear springs of the concrete elements (Figure 4b), where the maximum value of the shear stress is calculated based on Eq. (1) (Figure 4c).

$$
\begin{gathered}
\tau_{\text {max }}= \pm\left(1.6 f_{\text {telem }}{ }^{2}\left(-\sigma+f_{\text {telem }}\right)^{0.4}+0.15 f_{\text {telem }}\right) \\
\text { if }\left(\sigma \geq 3 f_{\text {telem }}\right) \\
\tau_{\text {max }}= \pm\left(1.6 f_{\text {telem }}{ }^{2}\left(-3 f_{\text {telem }}+f_{\text {telem }}\right)^{0.4}+0.15 f_{\text {telem }}\right) \\
\text { if }\left(\sigma<3 f_{\text {telem }}\right)
\end{gathered}
$$

Where,

$\tau_{\max }:$ maximum value of shear stress $(\mathrm{MPa})$

$f_{\text {telem }}$ : tensile strength of concrete $(\mathrm{MPa})$ $\sigma \quad:$ normal stress (MPa)

When a fracture occurs in the normal springs, the calculated shear stress is reduced according to the reduction in normal stress. As the result, the shear springs cannot carry the shear stress when the crack width of the normal springs exceeds $w_{\max }$ (Figure $4 \mathrm{~d}$ ).

(2) Steel elements

The geometry of steel elements is modeled in an accurate manner to properly account for the interlocking between concrete and a reinforcement bar (Figure 3). The normal springs of steel elements are modeled based on the stress-strain relationship of steel bars proposed by Shima et al. [9]. The stress-strain relationship used for the normal springs is represented by Eq. (2). Meanwhile, the shear springs used for the steel elements are assumed to be perfectly elastic.

$$
\begin{gathered}
\sigma=E_{s} \varepsilon \text { if }\left(\varepsilon<\varepsilon_{y}\right) \\
\sigma=f_{y} \text { if }\left(\varepsilon_{y}<\varepsilon<\varepsilon_{s h}\right) \\
\sigma=f_{y}+\left(1-e^{(\varepsilon s h-\varepsilon) / h}\right)\left(1.01 f_{u}-f_{y}\right) \text { if }\left(\varepsilon>\varepsilon_{s h}\right)
\end{gathered}
$$

Where,

$$
\begin{array}{lll}
k & : & 0.032\left(400 / f_{y}\right)^{1 / 3} \\
\sigma & : & \text { stress }(\mathrm{MPa}) \\
\varepsilon & : & \text { strain }
\end{array}
$$

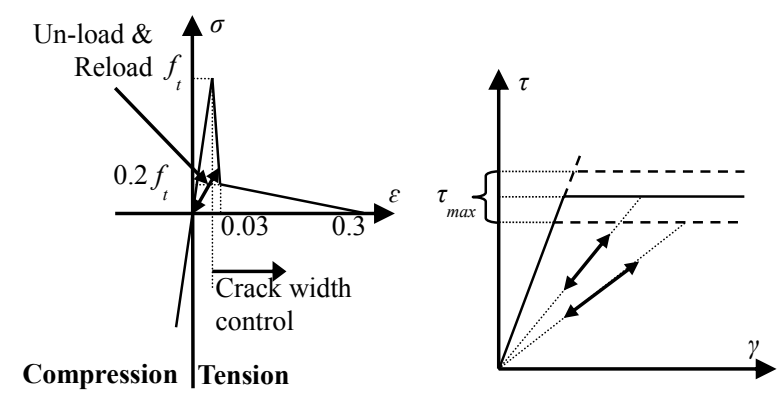

(a) Normal spring of concrete

(b) Shear spring of concrete

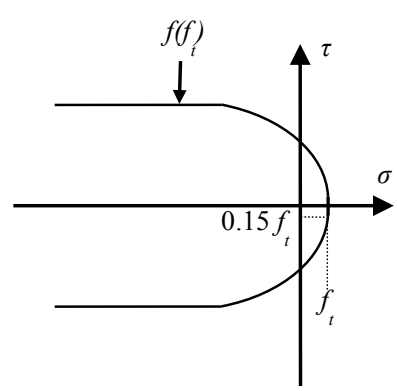

(c) $\tau_{\max }$ criterion for concrete

(d) Shear reduction factor 


$\begin{array}{lll}f_{y} & : & \text { yield strength (MPa) } \\ f_{u} & : & \text { tensile strength (MPa) } \\ \varepsilon_{s h} & : & \text { initial strain hardening, } \\ & & \text { assumed to be } 1.5 \%\end{array}$

(3) Concrete-steel interface

At the concrete-steel interface, the constitutive models of the normal springs and the shear springs have the same behavior as those of concrete elements (Figure 4a). However, in order to consider the concretesteel interface as a weak region, the tensile strength of the interface elements is assumed to be half that of concrete elements.

\section{DETAIL OF NUMERICAL SIMULATIONS}

\subsection{Numerical models}

Four numerical models are considered in this study. The simulation cases are listed in Table 1. Two numerical models involve experimental specimens with different stirrups arrangements along the anchorages selected from among those used in experiments, by Tasai et al. [3], who clarified the performance of mechanical anchorages with different local reinforcement arrangement along anchorages embedded in beam-column knee joints. In their experiments, different macroscopic behaviors were observed with different local reinforcement arrangements, but the reason for such variations was not clarified. In these models, stirrups along the anchorages in the beam-column joints are modeled as deformed bars. A further two numerical models are used for parametric studies in which the stirrups along the anchorages in the earlier models are modeled as plain bars. It is well understood that in the case of plain bars, slippage occurs easily between concrete and reinforcement because bond performance is determined only by the friction between concrete and reinforcement bar. If slippage occurs easily, it is expected that diagonal cracks open readily.

The notation of the variables in the two numerical models based on the experiments by Tasai et al. [3] is the same as that used for the original experimental specimens: BL1 means stirrups are provided only at the anchorage plates; BL2 means that stirrups are provided at the anchorage plates and along the development length of the anchorages. The two parametric studies are signified by BL1plain and BL2-plain.

Table 1: Detail of numerical models

\begin{tabular}{|c|c|c|c|c|c|}
\hline \multirow[t]{2}{*}{ Case } & \multirow[t]{2}{*}{ Parameter } & \multicolumn{3}{|c|}{$\begin{array}{l}\text { Material properties of } \\
\text { concrete }\end{array}$} & \multirow{2}{*}{$\begin{array}{l}\text { Number } \\
\text { of } \\
\text { Elements }\end{array}$} \\
\hline & & $\begin{array}{c}f_{c}^{\prime} \\
(\mathrm{MPa})\end{array}$ & $\begin{array}{c}f_{t} \\
(\mathrm{MPa})\end{array}$ & $\begin{array}{c}E_{c} \\
(\mathrm{MPa})\end{array}$ & \\
\hline BL1 & $\begin{array}{l}\text { Deformed stirrups at } \\
\text { anchorage plates }\end{array}$ & 33.2 & 2.58 & 24200 & 789067 \\
\hline $\begin{array}{l}\text { BL1- } \\
\text { plain }\end{array}$ & $\begin{array}{l}\text { Plain stirrups at } \\
\text { anchorage plates }\end{array}$ & 33.2 & 2.58 & 24200 & 766375 \\
\hline BL2 & $\begin{array}{l}\text { Deformed stirrups at } \\
\text { anchorage plates and } \\
\text { along the anchorages }\end{array}$ & 33.5 & 3.09 & 25800 & 858440 \\
\hline $\begin{array}{l}\text { BL2- } \\
\text { plain }\end{array}$ & $\begin{array}{l}\text { Plain stirrups as } \\
\text { anchorage plates and } \\
\text { along the anchorages }\end{array}$ & 33.5 & 3.09 & 25800 & 805706 \\
\hline
\end{tabular}

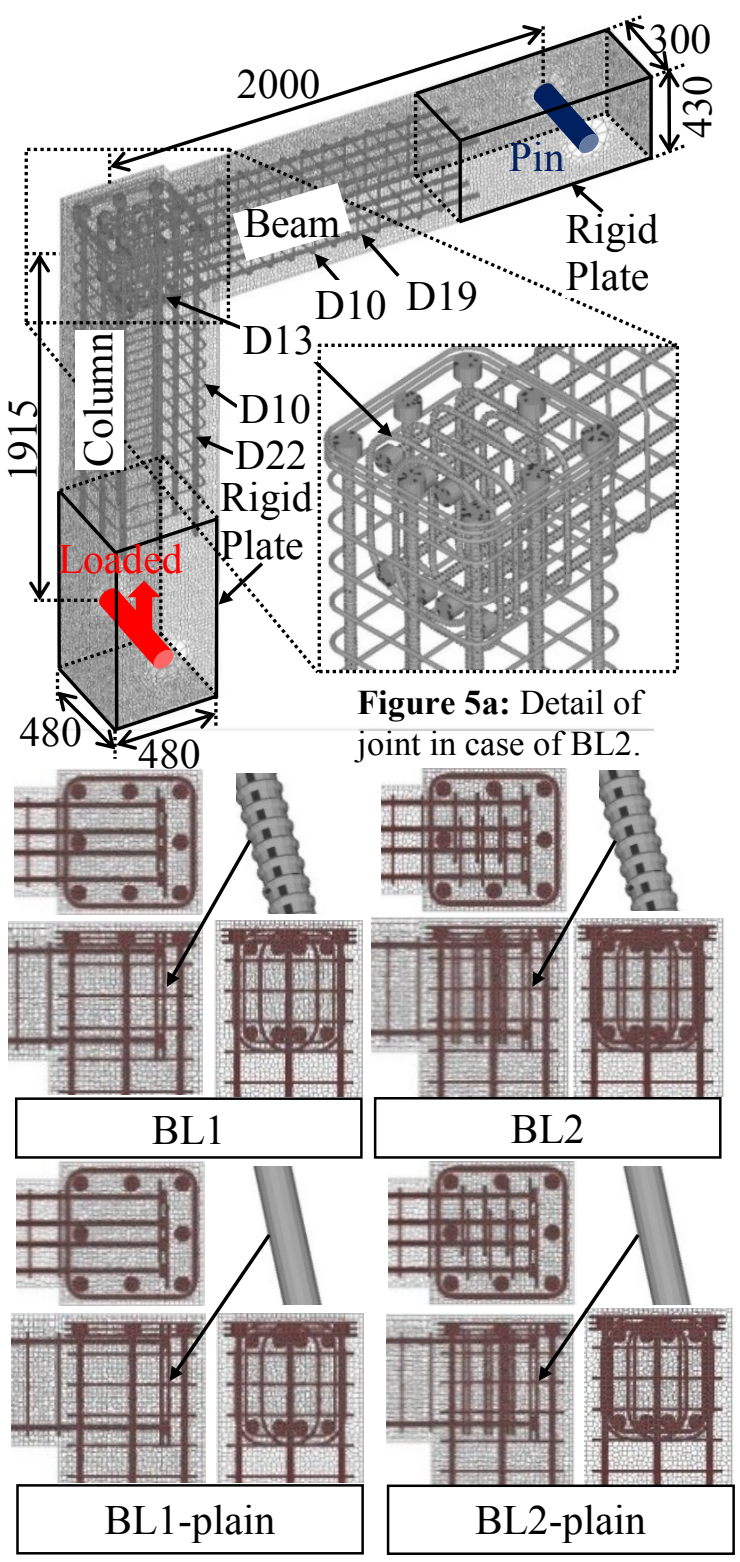

Figure 5: Geometries and boundary conditions of numerical models (units: $\mathrm{mm}$ ). 

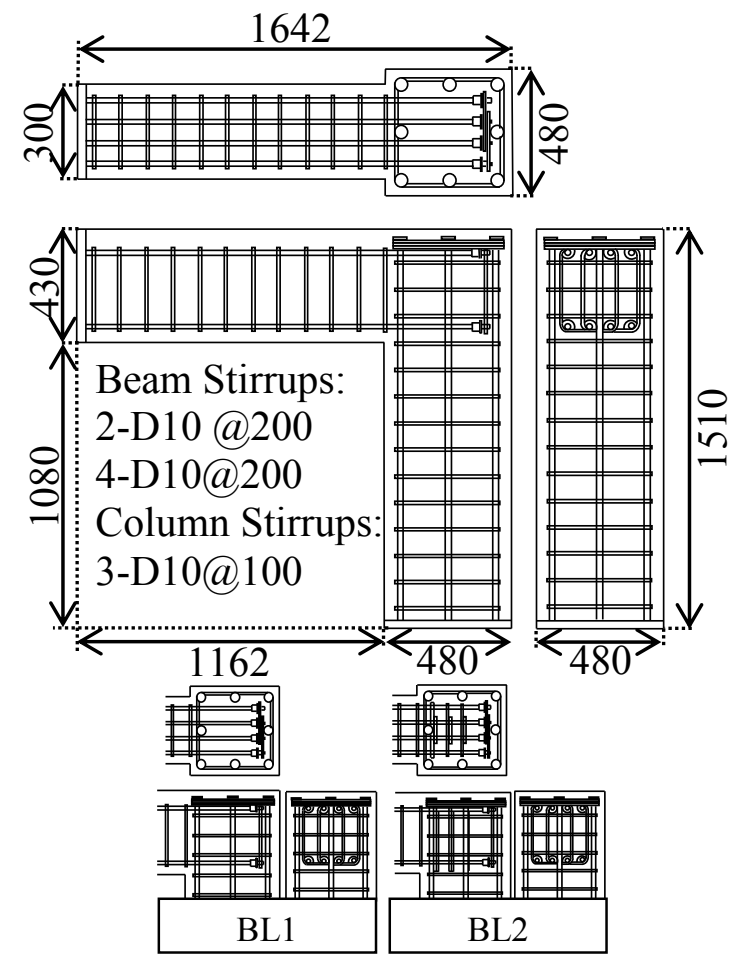

Figure 6: Experimental specimens.

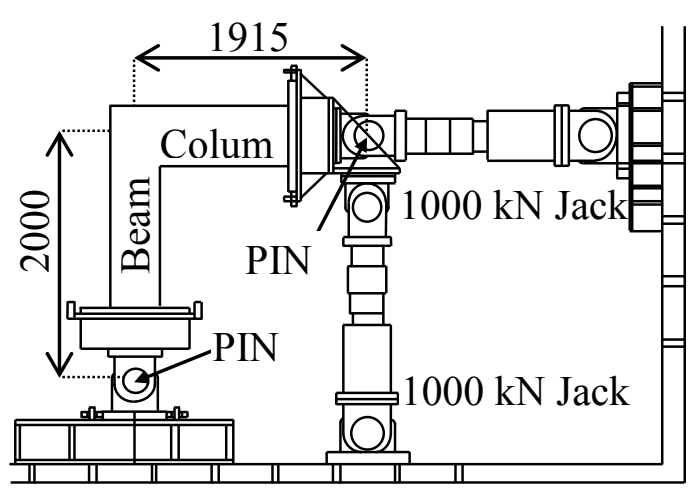

Figure 7: Experimental arrangement.

Table 2: Material properties of reinforcement bars

\begin{tabular}{cccc}
\hline Re-bars & Function & $\begin{array}{c}\text { Yield strength } \\
\text { (MPa) }\end{array}$ & $\begin{array}{c}\text { Modulus of } \\
\text { elasticity } \\
\text { (MPa) }\end{array}$ \\
\hline D22 & $\begin{array}{c}\text { Main reinforcement } \\
\text { of column }\end{array}$ & 392 & 193000 \\
\hline D19 & $\begin{array}{c}\text { Main reinforcement } \\
\text { of beam }\end{array}$ & 458 & 199000 \\
\hline D13 & $\begin{array}{c}\text { Stirrups at anchorage } \\
\text { plates }\end{array}$ & 806 & 193000 \\
\hline D13 & $\begin{array}{c}\text { Stirrups along } \\
\text { anchorage }\end{array}$ & 368 & 197000 \\
\hline D10 & $\begin{array}{c}\text { Beam and column } \\
\text { stirrups }\end{array}$ & 368 & 197000 \\
\hline
\end{tabular}

\subsection{Geometry of numerical models}

Figure 5 shows the geometries of the numerical models. All modeled dimensions are the same as those in the experimental specimens. For comparison, details of the original experimental specimens are included in Figure 6. The reinforcement arrangements in the numerical models match those of the experimental specimens, with deformed bars of $19 \mathrm{~mm}$ and $22 \mathrm{~mm}$ used as the main column and beam reinforcement, respectively. Stirrups in the beam-column joint portion of BL1 and BL2 are modeled as deformed bars of $13 \mathrm{~mm}$. Meanwhile, in cases BL1-plain and BL2-plain, the stirrups in the beam-column joint portion are modeled as plain bars of $13 \mathrm{~mm}$. In order to reduce the computational time, the stirrups of the beam and column are modeled as plain bars of $10 \mathrm{~mm}$. The material properties of the reinforcement in each model are shown in Table 2. High yield strength reinforcement is used for stirrups at anchorage plates to avoid yielding.

\subsection{Boundary conditions}

Figure 5 also shows the boundary conditions of the numerical models. For comparison, details of the experimental arrangement are shown in Figure 7. Rigid steel plates are modeled at the beam and column ends; modeled rigidity is such that deformation of the plates is prevented. To model the hinge condition in the experimental set up, pin elements are introduced into the steel plates. Only compressive forces are transferred through normal springs between the pins and the rigid plates; no tensile forces are transferred through the normal springs. Meanwhile, shear springs between the pins and the rigid plates are set to zero since friction is not allowed between the pins and the plates.

Since anchorage failure occurs due to a moment that tends to close the joint, this loading condition is the main interest in this study. Cyclic load applied in the experiment is not modeled in this simulation. In order to represent the moment that tends to close the beam-column joint, push load is applied to the pin in the rigid plate located at the end of the column, while the pin in the rigid plate located at the end of the beam is fixed. Monotonic displacement is applied in the simulation. This 
displacement is increased by $0.1 \mathrm{~mm}$ at each loading step. 1000 steps of displacementloading are applied in the simulation.

\section{RESULTS AND DISCUSSIONS}

\subsection{Load-displacement relationships}

The load-displacement relationships for BL1 and BL2, both simulations and experimental observations, are shown in Figures $8 \mathrm{a}$ and $8 \mathrm{~b}$, respectively. The loaddisplacement relationships for BL1-plain and BL2-plain are also included in Figure $8 \mathrm{~b}$. Maximum loads are included in Table 3. The load is defined as the load applied on the pin in the rigid plate located at the end of the column, while the displacement is calculated based on the drift angle. In cases BL1 and BL2, the maximum loads given by the simulation results are roughly the same as those observed in the experimental specimens, with discrepancies of $5-10 \%$. The simulation results are underestimated by $5 \%$ and $10 \%$ respectively in cases BL1 and BL2. Thus, the simulated maximum loads are in overall good agreement with the experimental results.

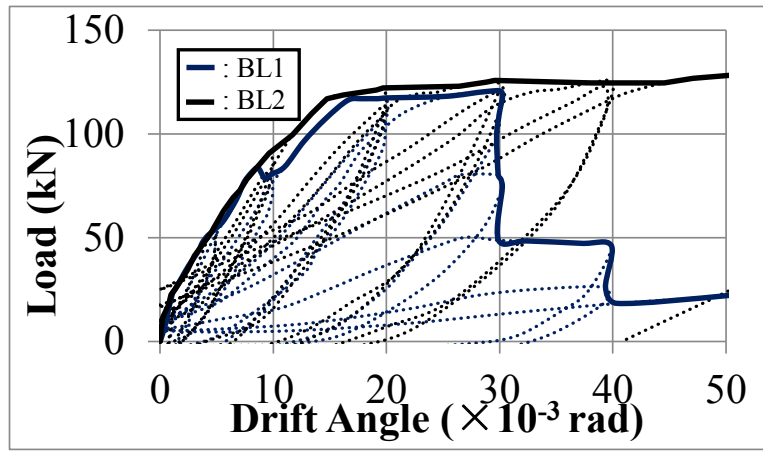

Figure 8a: Experimental results.

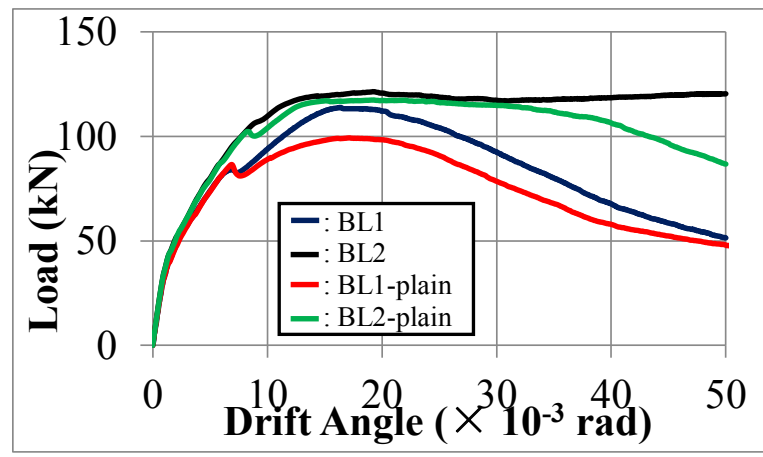

Figure8b: Simulation results.

Figure 8: Load-displacement relationships.
Table 3: Maximum loads

\begin{tabular}{cccc}
\hline Case & Parameter & \multicolumn{2}{c}{ Maximum load } \\
\cline { 3 - 4 } & & $\begin{array}{c}\text { Experiment } \\
(\mathrm{kN})\end{array}$ & $\begin{array}{c}\text { Analysis } \\
(\mathrm{kN})\end{array}$ \\
\hline BL1 & $\begin{array}{c}\text { Deformed stirrups at } \\
\text { anchorage plates }\end{array}$ & 120.3 & 113.8 \\
\hline BL1-plain & $\begin{array}{c}\text { Plain stirrups at } \\
\text { anchorage plates }\end{array}$ & - & 99.4 \\
\hline BL2 & $\begin{array}{l}\text { Deformed stirrups at } \\
\text { anchorage plates and } \\
\text { along the anchorages }\end{array}$ & 135.1 & 122.3 \\
\hline BL2-plain & $\begin{array}{c}\text { Plain stirrups as } \\
\text { anchorage plates and } \\
\text { along the anchorages }\end{array}$ & - & 117.4 \\
\hline
\end{tabular}

It is predicted in the simulations that the maximum load in the case of BL1-plain (plain stirrups) is approximately $14 \%$ lower than that of BL1 (deformed stirrups), while the maximum load in the case of BL2-plain (plain stirrups) is approximately $4 \%$ lower than that of BL2 (deformed stirrups).

After exceeding the maximum load, behavior varies depending on the failure mode of the beam-column joint. It is observed in the experiment that anchorage failure in the joint occurs in case BL1 and, furthermore the load decreases significantly once the maximum load is exceeded. On the other hand, flexural failure occurs in case BL2 and the load does not decrease after exceeding the maximum load in this case. The same failure patterns are predicted by the simulations. In case BL1plain, the load decreases significantly after exceeding the maximum load which is similar to BL1. It indicates anchorage failure in this case. Meanwhile, the failure behavior in BL2plain is almost the same as that in BL2, but the load starts decreasing at a drift angle of around $0.030 \mathrm{rad}$. It can be concluded that if plain bars are used as stirrups along the anchorages, the performances of the beam-column joints change: the capacity and the failure behavior. By studying the internal stress and cracks using numerical simulation, the cause of the change in the performances in plain stirrups cases is investigated.

\subsection{Surface cracks}

A 3D representation of the surface cracks in cases BL1 (anchorage failure behavior) and BL2 (flexural failure behavior) is shown in Figure 9. Figure 10 shows the crack patterns 
for all simulation models where BL1 and BL2 are compared with photos obtained in the experiments after failure.

Generally, the simulations match the observed crack patterns well. In all cases, the simulations predict that diagonal cracks, propagating from the anchorage plates of top longitudinal bars of the beam to the corner of the beam-column joint (1a) and from the anchorage plates of the middle longitudinal bars of the column to the corner of the beamcolumn joint (1b), occur on both sides of the numerical numericals. In cases BL1 and BL2, cracks were observed at the same locations in the experimental specimens. In cases BL1 and BL1-plain, the simulation results predict damage at the top surface, which indicates anchorage failure in the beam-column joints (2). However, the concrete spalling in the experimental specimens is not well simulated. In case BL2, the simulation predicts that cracks behind the anchorage plates would occur on the top surface (2). Furthermore, the flexural cracks predicted in case BL2 are wider than in BL1 and BL1-plain, which indicates flexural failure in the beam-column joint ( 3). Almost the same behavior is predicted in case BL2-plain, but cracks behind the anchorage plates in this case are wider than in BL2.

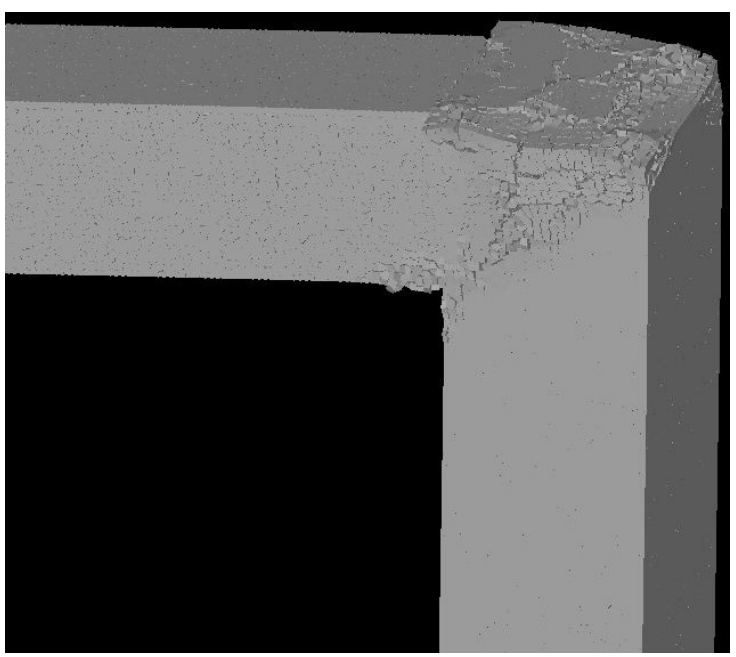

Figure 9a: BL1.

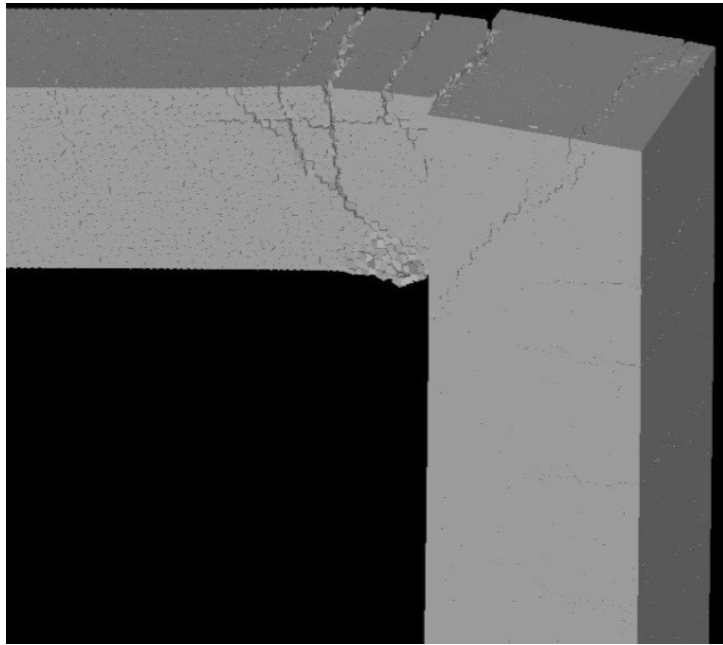

Figure 9b: BL2.

Figure 9: Surface cracks in 3D (deformation $\times 3$ ).

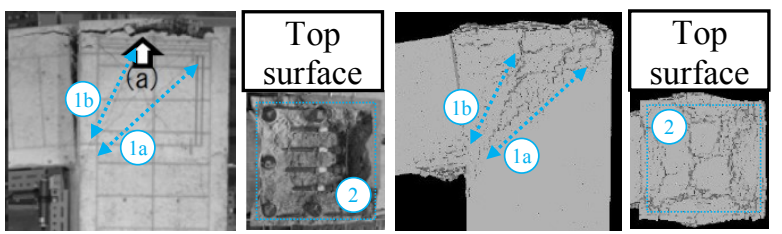

Experimental observation

Simulation

Figure 10a: BL1.

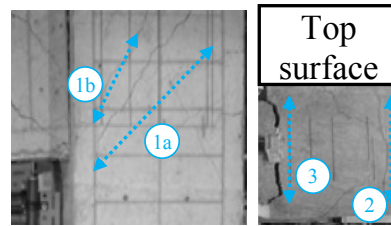

Experimental observation

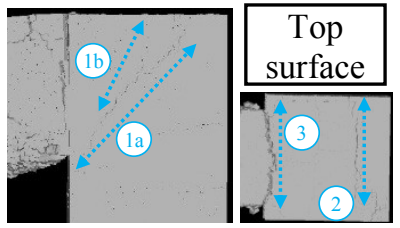

Simulation
Figure 10b: BL2.
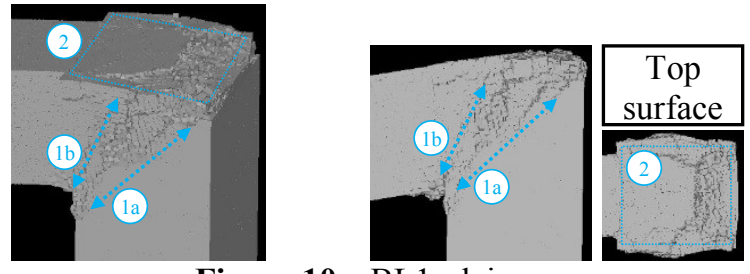

Figure 10c: BL1-plain.
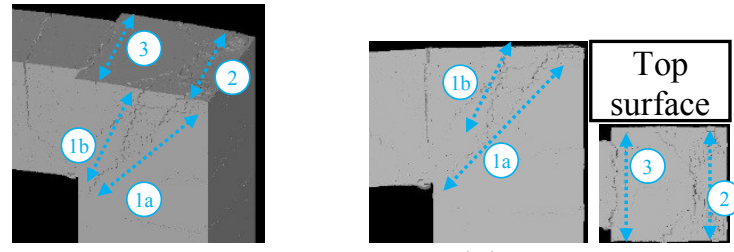

Figure 10d: BL2-plain.

Figure 10: Surface cracks (deformation $\times 3$ ). 


\subsection{Effect of shape of stirrups along the anchorages the plain bars}

Figure 11 shows the internal stress distributions in cases BL1, BL2, BL1-plain, and BL2-plain at a drift angle $0.010 \mathrm{rad}$, at a cross section where the beam reinforcement bars are present. These internal stress distributions in the beam-column joints show that there is bonding along the development length of the anchorages in all cases at the early stage of loading. In cases BL2 and BL2plain, there is improved bond performance along the development length of the anchorages because of the stirrups provided along the anchorages. As the drift angle increases, diagonal cracks occur in the beamcolumn joint (1), but the occurrence of these diagonal cracks is delayed in cases BL2 and BL2-plain, because of the increased bond performance along the development length of anchorages. In cases BL2 and BL2-plain, diagonal cracks occur at the same drift angle, at a drift angle of around 0.009 rad which is indicated by a slight drop in load in case BL2plain. Meanwhile in case BL2, since the opening of the diagonal cracks is smaller, the load does not drop as BL2-plain. In cases BL1 and BL1-plain, diagonal cracks also occur at the same drift angle, which is indicated by a slight drop in load at a drift angle of around $0.007 \mathrm{rad}$. This means that bond performance along the development length depends on the number of stirrup and is not affected by the type of stirrup. As the drift angle increases, the load increases again until the maximum load is reached. Cracks propagate behind the anchorage plates because the interface between anchorage plates and concrete is weak in tension. The diagonal cracks and these cracks behind the anchorage plates join together. Moreover, they penetrate to the top surface of the beam-column joint (2) . Consequently, if the diagonal cracks open wider without any restriction, the cracks penetrating to the top surface of the beamcolumn joint also wider.

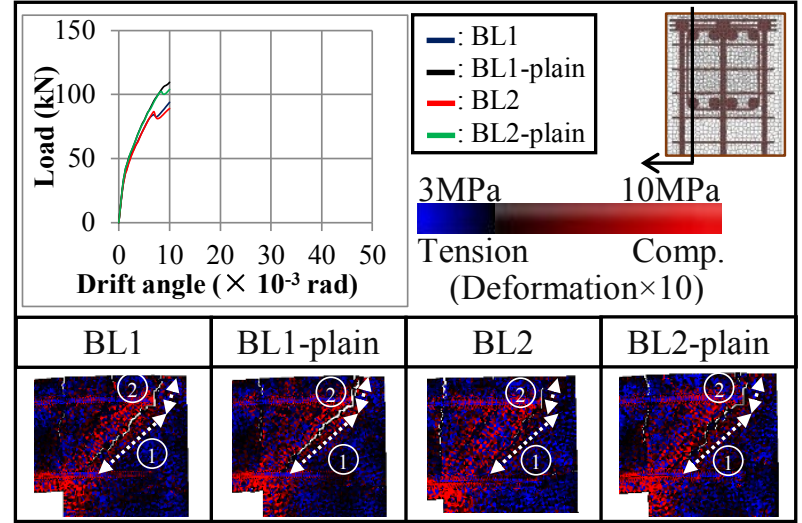

Figure 11: Internal stresses at a drift angle of $0.010 \mathrm{rad}$.

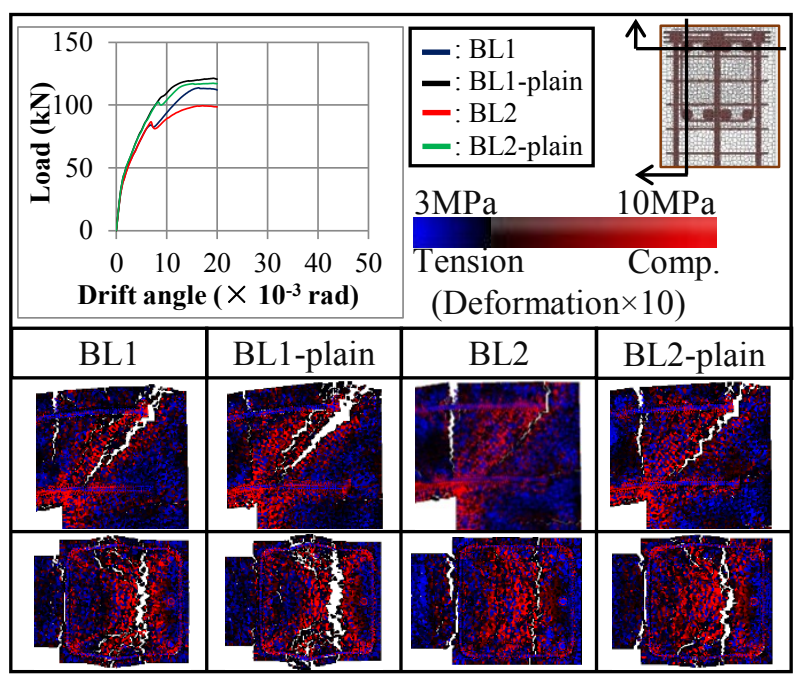

Figure 12: Internal stresses at a drift angle of $0.020 \mathrm{rad}$.

Figure 12 shows the internal stress distributions in cases BL1, BL2, BL1-plain, and BL2-plain at a drift angle $0.020 \mathrm{rad}$, at a cross section where the beam reinforcement bars are present. The increase in load is greater for BL1 than for BL1-plain, because the opening of diagonal cracks is greater for BL1plain than for BL1. The same behavior is also predicted in cases BL2 and BL2-plain. It means that the opening of diagonal cracks is affected by the type of stirrup. If plain bars are used as stirrups along the anchorages, slippage occurs easily and diagonal cracks then open readily.

The opening of these diagonal cracks significantly affects the macroscopic behavior. As diagonal cracks open easily, damage occurs easily at the top surface of the joint and it is hard for a diagonal compressive strut to form, so there is a significant drop in load after the 
maximum load and anchorage failure occurs in cases BL1 and BL1-plain. Meanwhile, in case BL2, as diagonal cracks do not open easily, no damage occurs at the top surface of the joint, so the load does not decrease beyond the maximum load and flexural failure occurs in case BL2. Furthermore, because the opening of diagonal cracks in case BL2-plain is greater than in BL2, cracks at the top surface of the joint in this case are wider than those in BL2.

\section{CONCLUSIONS}

Based on the study of the effect of diagonal cracks opening on the failure behavior of beam-column joints with mechanical anchorages, the following conclusions can be drawn.

1. The simulations of beam-column joints with mechanical anchorages give good predictions in terms of load-displacement relationships and surface cracks. The simulation also captures failure behavior seen in experiment, in which anchorage failure occurs in case BL1 and flexural failure occurs in case BL2. Based on the simulation results, different performances are predicted with different types of stirrups: the capacity and the failure behavior. The capacity in the case of BL-1 plain is approximately $14 \%$ lower than that of BL1, while the capacity in the case of BL2-plain is approximately $4 \%$ lower than that of BL2. Anchorage failure occurs in case BL1plain and the load starts decreasing at a drift angle of around $0.030 \mathrm{rad}$ in case BL2-plain.

2. Through a study of the internal stresses and cracks modeled by $3 \mathrm{D}$ RBSM, it is clarified that bond performance along the development length of the anchorages depends on the number of stirrup and is not affected by the type of stirrup. Meanwhile, the opening of diagonal cracks is affected by the type of stirrup along the anchorages. When plain bars are used as the stirrups, slippage occurs easily between concrete and reinforcement and diagonal cracks then open readily.

3. The opening of diagonal cracks significantly affects the macroscopic behavior. When diagonal cracks open easily, damage occurs at the top surface of the joint, leading to a decrease in capacity. Furthermore, anchorage failure occurs. Meanwhile, when diagonal cracks do not open easily, no damage occurs at the top surface of the joint and the capacity is higher. Flexural failure occurs in this case.

\section{REFERENCES}

[1] Wallace, J. W., McConnel, S. W., Gupta, P., and Cote, P. A. 1998. Use of Headed Reinforcement in Beam-column Joints Subjected to Earthquake Load. $A C I$ Structural Journal 95:590-606.

[2] Chun, S. C., Lee, S. H., Kang, T. H. K., and Wallace, J. W. 2007. Mechanical Anchorage in Exterior Beam-column Joints Subjected to Cyclic Loading. $A C I$ Structural Journal 104:102-112.

[3] Tasai, A., Kusunoki, K., Kiyohara, T., and Adachi, T. 2012. Structural Performance of Reinforced Concrete Exterior Beamcolumn Joint with Headed Bars. Proceedings of the $15^{\text {th }}$ World Conference on Earthquake Engineering.

[4] Eddy, L., and Nagai, K. 2015. Effects of Stirrups Arrangement in Failure of Beamcolumn Joint with Mechanical Anchorages by 3D Discrete Model. Proceedings of the $37^{\text {th }}$ Japan Concrete Institute: pp.313-318.

[5] Wang, T, Eddy, L., and Nagai, K. 2014. Numerical Simulation of Failure of Beamcolumn Joint with Mechanical Anchorage by 3D Discrete Analysis. The $6^{\text {th }}$ Asia Pacific Young Researchers and Graduates Symposium.

[6] Nagai, K., Hayashi, D., and Eddy, L. 2014. Numerical Simulation of Failure of Anchorage with Shifted Mechanical Anchorage Bars by 3D Discrete Model. Advances in Structural Engineering 17:861-870.

[7] Kawai, T. 1978. New Discrete Models and Their Application to Seismic Response Analysis of Structures. Nuclear Engineering and Design 48:207-229.

[8] Nagai, K., Sato, Y., and Ueda, T. 2005. Mesoscopic Simulation of Failure of Mortar and Concrete by 3D RBSM. Journal of Advanced Concrete 
Technology 3:385-402.

[9] Shima, H., Chou, L. L., and Okamura, H. 1987. Micro and macro models for bond in reinforced concrete. Journal of the Faculty of Engineering, The University of Tokyo 39(2):133-194. 